\title{
Teaching research methodology: Implications for psychology on the road ahead
}

\author{
Claire Wagner \\ David Maree
}

Department of Psychology, University of Pretoria, Lynnwood Road, Brooklyn, 0181, Pretoria, South Africa cwagner@postino.up.ac.za

Department of Psychology, University of Pretoria, South Africa

This article examines the ways in which academics who teach undergraduate research methodology courses conceptualise research and scholarship and the role these aspects play in the way they construct their courses. In-depth interviews were conducted with nine academics who have been intimately involved in constructing social science research courses at South African universities. Carspecken's (1996) critical hermeneutic method was adapted and applied to the interview material. Four beliefs held by participants on how and why their course curricula came into being are presented. The first and second beliefs relate to the position of some of the participant academics as expert researchers and also expert teachers of research. The third belief is that the construction of curricula is affected by what has traditionally been taught to students about research, but also by severe criticisms of historical content. Political repositioning in South Africa is the fourth belief held by participants about what has shaped research courses. Academics in psychology need to take cognisance of the fact that methodological debates in the social sciences and current thinking about knowledge and learning are pointing to new directions in how we should train students to study the human realm. If we want to remain relevant to the social world in which we live, we need to discuss these directions and forge a new way of acting in this world.

Although psychology is diversifying into a wide variety of fields, a common point remains the use of a scientific method for understanding human behaviour (Stanovich, 2004). In its White Paper on Science and Technology released by the Department of Arts, Culture, Science and Technology (1996), the South African government emphasises the role of social science research in particular as an agent of social change and as a contributor to the national system of innovation. Tothill and Crothers (1997) highlight the importance of 


\section{openUP}

'shaping Social Science research methodology teaching in South Africa for the immediate and long-term future' (p. v) to improve the standard of education received by students in the social sciences, as future researchers.

In a series of articles in the South African Journal of Psychology (SAJP) (Van Staden \& Visser, 1990; Visser \& Van Staden, 1990) and the South African Journal of Science (Van Staden \& Visser, 1992), Van Staden and Visser postulate that, although there was a fair degree of overlap between research methodology curricula and the topics being reported on in the SAJP, psychology students would only be able to understand $60 \%$ of the statistical methods that were used, extending this figure to $76 \%$ if the content included the field of reliability and validity coefficients. Qualified psychologists are in the same position as sociologists when it comes to understanding methods used in the international literature (Visser \& Van Staden, 1990). Although Van Staden and Visser's research provides a picture of the trends in research methodology at the time, the study was conducted more than a decade ago and examines only the overlap between curriculum content and research published in an academic journal.

Many factors impact on the nature of a research methods curriculum. These include where the course instructors position themselves in the debate on whether or not different research methods are applied to answer different research questions, the application of inductive and deductive methods in different areas of research, the issue of funding (many research grants have positivistic aims and objectives that force researchers to use specific research approaches), and so on (for a more comprehensive discussion see Wagner and Okeke, 2006). Little seems to be known, however, about the inherent assumptions that academics have about research and the influence this has on the way that they construct undergraduate research methodology courses in South Africa, especially in the light of changes in higher education policy.

It is important to examine the assumptions on which curriculum development is based, as our paradigms support and sustain what we base the transmission of knowledge on (Brew, 2003; Chin \& Russo, 1997; Schubert, 1986). As Brew (2003, p. 9) argues, 'heightened knowledge about the ways in which academic researchers conceptualise research and scholarship throws new light on the relationship between teaching and research'. This article attempts to explore academics' conceptualisations of research and scholarship and the role that they play in the way they construct their courses. While there may be nothing inherently wrong with current courses, it is important to carefully consider the assumptions behind the choice of curricula and the implications of these.

\section{RESEARCH DESIGN}

\section{Scope of the study}

In a preliminary phase of this study, data were collected regarding the content of undergraduate research courses at South African universities. An examination of the content 
of the courses revealed that there is a heavy reliance on methods that are traditionally linked to the positivist paradigm. This refers to the view of quantitative research that has been popularised by many undergraduate textbooks, namely that it is based on positivist tenets and equated with empiricism and experimental designs. It is placed in direct opposition to paradigms that 'describe and illuminate the meaningful social world' (Silverman, 1993, p. 21), such as interpretivism. It also revealed that alternate paradigms focusing on philosophies that dictate the use of qualitative methods are increasingly included in methodology courses and juxtaposed against or used to supplement so-called positivist approaches to research. The results in their entirety can be found in Wagner (2003). This article focuses on information collected during in-depth interviews about the assumptions that inform the way academics construct research courses.

\section{Sample}

Although this study falls within the discipline of psychology, as many social science research courses as possible were included to ensure applicability to a larger group of people. An attempt was made to gain as much diversity as possible by targeting universities in the historically advantaged and disadvantaged categories and in different geographical regions, as well as those whose training models and courses represent a variety of topics. The ability of the participant to provide adequate information about the construction of the course (i.e., a person intimately involved in its development) was also a requirement. Sixteen potential participants were selected and of these, nine were willing to be interviewed. The characteristics of the sample were as follows: five were female and four male, the majority of interviewees were young or classified themselves as junior staff members (only two had doctorates at the time of the interviews), and one black person and eight white people participated. Four of the interviewees were located in Gauteng and five in the Western Cape, KwaZulu Natal, and the Free State.

The majority of interviews were conducted with academics at historically advantaged universities. Very little response was received from individuals at what was known at the time of the interviews (2002) as historically black universities (HBUs), who were contacted mostly by email due to their geographical location (all universities outside the Gauteng area were contacted via email). The poor response from HBUs could be related to the legacy of apartheid: different education structures and institutions were made available to different groups of people in South Africa, and relationships were not encouraged between institutions. Although apartheid has been dismantled, the reluctance of institutions to develop closer relationships seems to remain. This could point to a methodological flaw in the research: not making an effort to meet with potential participants in person. The Tothill and Crothers (1997) study also reported a low response rate from HBUs. These researchers advised that 'Historically White Universities should not be seen as the yardstick against which research methodology training should be measured' (Tothill \& Crothers, 1997, p. vi). 
In the interval between the initial survey of the content of courses and the subsequent interviews with lecturers, many of the courses had changed their focus. In most of these cases the change related to a shift in content dealing with quantitative topics only to content that included mixed methods approaches (i.e., how to combine quantitative and qualitative research).

\section{Procedure}

A semi-structured interview guide was drawn up based on questions about the content of the courses surveyed earlier, information from the literature on teaching research methodology, and questions about the way in which interviewees constructed their courses. The Research and Ethics Committee of the Faculty of Humanities at the University of Pretoria approved the study. Each interviewee gave his or her permission to tape-record the interview. Participants who were not in close geographical proximity to the researcher were asked to complete an electronic version of the interview guide and, if necessary, some follow-up questions were asked via email. Four interviews were conducted face-to-face and five via email.

\section{Data analysis}

The interviewer (first author) transcribed the taped interviews verbatim for purposes of analysis. Carspecken (1996) outlines an approach for data analysis from a critical hermeneutic epistemology. Critical theorists propose that power is circulated in particular ways in higher education:

It is clear ... that any 'regime of truth' involves privileging certain types of discourse, sanctioning certain ways of distinguishing true from false statements, underwriting certain techniques for arriving at the truth, according a certain status to those who competently employ them, and so forth. (McCarthy, 1994, p. 253)

These regimes are usually not apparent social realities. They are held in place by conditions that lie deeper than what is evident on the surface, thus prompting critical theorists to search for the underlying mechanisms that maintain them. If it is accepted that social reality has more than one layer and that people are not aware of the deeper structures that govern their lives, it can be said that they accept the way in which society functions. Critical theorists refer to this as 'false consciousness' and maintain that this functions to reproduce the status quo, which benefits powerful individuals or groups. Social reality is thus problematic in certain cases as it oppresses people who are not privileged. Critical theory goes beyond exposing and sensitising people to the taken-for-granted, established order, to propose alternative actions that people can take in order to transform their social reality. Although critical researchers do not claim a privileged position of authority and are limited by their adherence to the context in which they do their research, the hermeneutic 
process allows them to form a better understanding of phenomenona and to live themselves into the experience that they encounter (Kincheloe \& McClaren, 2000).

Carspecken's (1996) method was adapted and applied to the interview material. Coding was included as a complementary technique to thematic analysis to enable the researcher to distinguish patterns "where we identify a "type" of occurrence by virtue of it being perceived as an underlying "common form" found in different contexts' (Kelly, 1999, p. 412). A reconstructive analysis was performed on the data in terms of which meaning units were identified, and assigned code labels and numbers to establish patterns and generate themes by merging certain codes. Carspecken (1996) notes that many criteria could serve to place emphasis on certain aspects of the codes, but that the validity of the emphasis should be foremost in the researcher's mind.

This in turn enabled the researcher to choose suitable parts of the data for meaning reconstruction (fleshing out and explicitly stating what is said by participants). Nine categories referred to as 'beliefs' were generated. Naturally there are many different types of meaning that could be conveyed in an interaction. The way in which researchers understand what the interviewees are saying to them depends on their own assumptions and context. Willig (2001) argues that 'these are not seen as "biases" to be eliminated; instead they are seen as a necessary precondition for making sense of another person's experience' (p. 66). According to Willig (2001), therefore, knowledge generated in this manner becomes reflexive, as the researcher's role in knowledge production is recognised. Meaning reconstruction is not the focus of this analysis; instead the emphasis is on the union between the researchers' reference system (what is familiar to them) and the reference system of research participants that is not familiar to researchers. Hermeneuticians assume that the reference system of participants is unfamiliar to researchers, but, in the case of this study, the authors know many of the aspects that academics are grappling with regarding undergraduate methodology courses. Both the interviewer and the participants brought certain baggage (social and cultural background) to the interviews and thus the challenge was to achieve a viewpoint that coincided with both of these realms, referred to by Gadamer (1989) as ‘a fusion of horizons'.

\section{RESULTS AND DISCUSSION}

Four beliefs held by the interviewees about the construction of undergraduate research courses are presented and discussed below. These particular beliefs were chosen to illustrate how different kinds of power relations manifested in the way that the interviewees spoke about the undergraduate research curricula.

\section{The researcher as expert and expert teacher}

Two related beliefs are discussed here: (1) undergraduate research methodology courses should be constructed by means of consensus, and (2) undergraduate research curricula 
should be constructed based on the expertise and research experience of academics. Almost without exception, decisions about what to include in the undergraduate research curricula are made within a dialogical activity. This means that the people responsible for the course sit around a table or use a virtual mechanism such as email to discuss content, structure, and so on. Communicating ideas to colleagues has the function of reaching a consensus. As Mourad (1997), following Rorty, argues: 'scholars should think of knowledge as simply a name or label for the subject of agreement among any group of humans concerning belief, values and action ...' (p. 118).

Participants position themselves as experienced researchers or people who are interested in the field and use this expertise to inform curriculum content. Not all of the interviewees perceive their colleagues as equally competent, however: 'We have many jokes, like when you get study material that is incomplete or incorrect, and the more ignorant facilitator may facilitate it as the truth'. This participant views this as a disadvantage to the student. An invisible hierarchy amongst research lecturers thus seems to exist, but it is not clear how this plays out when academics are attempting to achieve consensus. In their study on research courses at tertiary institutions, Tothill and Crothers (1997) found that less than half of methodology lecturers were conducting research into issues of methodology and concluded that "it would thus appear that the role of "specialist" is defined by academics in terms of teaching areas, rather than research' (p. 14). The social scientist is cast as the expert and further as the expert teacher (Bradley, 1998).

Main decision makers are usually senior colleagues within a department, such as course and paper leaders and 'obviously also our head of department'. Heads of departments either give direction to the development of the course or they have the authority to grant final approval of the course. In one case, a programme coordination committee in the department evaluates the curriculum. Discussions are held on a formal or informal basis. Electronic means are also used to collect information. As an interviewee explained, 'These days it's so easy to go on the Internet and look for one university in the United States and see how they do their thing'. When a group of academics working in an institution have to consult all the departments of a particular discipline on various campuses, electronic communication is often used to discuss the content of the course. Feedback from colleagues about the course is processed and used to revise subsequent curricula. Interviewees also used words such as 'workshopped' or 'brainstormed' when asked how they developed their course. Academics are thus the main stakeholders who decide on the essential elements to which students are introduced in an undergraduate research course.

When interdisciplinary research modules are developed across departments in faculties, some departments believe that they are marginalised. Although these departments feel that they have a unique contribution to make to the curriculum, they are not consulted, and it is often the 'bigger' departments that decide on the content of the curriculum and assume that the content is applicable to all other departments. Consensus by a majority can thus leave minorities feeling left out of the process.

Once a 'common philosophy' of what the content should be is agreed on, the various 
topics are assigned to lecturers, based on their interest and expertise. The lecturers select reading materials, develop the course and lead discussions with students. One participant justified this approach by saying that:

All the lecturers concerned have good track records of research and had experience of teamteaching together. No need was felt to undertake literature reviews or surveys as the staff felt they knew the skills that students in the discipline needed.

This participant called this ‘a very pragmatic approach'. Academics also apply their research experience to the content of courses. This experience includes conference attendance where pertinent issues on the national and international research agenda are presented, personal publishing records, working with renowned people in their field, the lecturer's relationship with industry, and supervision of postgraduate students, in the course of which gaps in students' research skills are identified and used to restructure the undergraduate curriculum. In the latter case, the construction of the content of undergraduate courses becomes a process of modification and improvement over the years, which is based on the skills that students need to acquire for further studies. Lecturers thus believe that many years of experience of working with students qualifies them to develop the curriculum to suit the needs of their students as a very specific audience.

Sometimes a lack of expertise in a particular area results in courses becoming focused on a specific area of research methodology. For example, even though some departments would like students to have a 'balanced' view of research, they can only present qualitative courses due to the lack of personnel who can teach quantitative methods at a certain level. If course constructors have a specialised field of expertise in research, such as psychometrics, they focus the content of the course on this field.

Academics who were interviewed seemed unaware of the impact of their positioning as expert researchers and teachers on the curriculum of their research courses. Honneth's (1999) concept of mißachtung or social disregard appears to be relevant. Mißachtung refers to people being disrespected or not receiving recognition in social interactions. It can be argued that the consensus achieved regarding the curriculum for a research course is the result of conversations held between academics that exclude other significant voices. Power is thus not necessarily exercised in interactions between lecturers. It manifests in the curriculum that is presented to students as a taken-for-granted situation. Lecturers' dominance over the students is maintained in the dialogical activities that they undertake with colleagues that confirm their position of authority in the academic society. Students recognise this authority and consent to it. Kincheloe and McClaren's (2000) definition of power from a critical theory perspective, namely as oppressive, is applicable here. The current manner of curriculum construction, as defined by the interviewees, results in a situation where the lecturer determines the content as well as the acceptable criteria for assessing students' competencies.

The disregarding of students' needs may be a reason for the negative attitudes they display towards research courses. Students could also experience powerlessness, which Claire Wagner and David Maree 
'arises from passive acceptance of oppressive cultural "givens", or surrender to a "culture of silence"' (Bhana, 1999, p. 235). Some of the ways in which students may react to this include mechanisms of passive resistance, such as a dependency on lecturers and failing the research course many times: 'When I presented research I developed a remedial programme because I had a lot of students who said they couldn't do it [research], it's difficult, and they try to postpone and postpone until the end [of the course] ...' (translated from Afrikaans by authors).

In addition, when research methodology is taught separately from a substantive discipline, or even in an interdisciplinary model as is the case at some universities, Williams (2000) argues that students may not understand the link between research and the profession that they are pursuing, and therefore do not appreciate its relevance to their future undertakings. This sentiment is captured in one interviewee's perception of students' attitudes towards research:

Why do I want to research because I'm a nurse in a ward; what do I want to do with a subject like research? I'm a psychologist: I want to do therapy, why must I do research? (Translated from Afrikaans by authors)

There is an alternative view of the problems that occur when constructors of courses place themselves in the position of the researcher as expert teacher. This is that the knowledge differential between lecturer and student is necessary for learning to take place. Principles of curriculum design may also intervene in the ability of academics to position themselves differently in the process of constructing a course.

\section{Tradition and curriculum}

Another factor affecting the curriculum is historical verification of the content. In other words, does the course adhere to traditions inculcated by experts over time (Lyotard, 1984)? Some of the participants mentioned the role of tradition (what they had been subjected to in their own studies) in informing the choices they made in constructing the course. This tradition is held within the legitimated discourses of power that Kincheloe and McClaren (2000) identify as operating in academia, and which dictate the content, teaching methods, materials, and philosophies suitable for specific courses.

Tradition is, however, often the focus of criticism and is blamed for the way that students perceive research methodology. The academics who were interviewed about the way they construct research courses talked about reviewing tradition and replacing it with new material if necessary so that students' attitudes towards research could change. 'New material' is represented first and foremost by qualitative methods as an improvement on having only quantitative methods present in the curriculum; thus the distinction between tradition and innovation is made on a methodological level. By acknowledging the limitations in curricula of the past, academics actively seek to change the discourses, but 
by doing so they may be instituting new hegemonies that may still limit students' success as researchers.

Perhaps because the research participants in this study were so homogeneous in terms of educational background, age, and race, few unusual ideas were evident. Statements adhered to similar norms in terms of education, and specifically research methodology courses (found in the literature), which may indicate the extent to which tradition is still ingrained in the ideas of the interviewees. The most radical approach to curriculum construction that was mentioned was the idea of not teaching theory merely for the sake of it. One way of avoiding this is to exclude 'unnecessary technical methodological details' from the curriculum. Another way is to integrate research into the modules of a substantive discipline instead of having research methodology as a module on its own. At one university, for example, students are taught how to do research in their community project module. This structure counteracts the concern of Williams (2000) that students are being taught to be technicians instead of researchers in a substantive discipline.

\section{Political repositioning in South Africa}

Historically black and white universities alike have to deal with students who come from diverse educational and socioeconomic backgrounds. Academics who were interviewed believe that curriculum development needs to take place within this reality. One participant at an HBU explained his position as follows: 'To move into a first class and talk about the positivistic paradigm [is unrealistic as students] don't know what you are talking about to the point when you lecture a first module in statistics you teach students to use their calculators'. If certain course content relies on the mathematical ability of students and this is poor, it limits the type of content that can be included in courses. As a consequence, this content is often shifted to postgraduate level. This illustrates interviewees' belief that there are aspects external to the research curriculum (such as students' lack of an adequate educational history) that also need to be dealt with in the research class.

Two interviewees described the state of their disciplines (and the effect this had on how they trained students to conduct research) in terms of the political past of South Africa. According to an interviewee in an anthropology department, ethnographic research often disguised a hidden agenda based on political and religious motivations. This agenda seems to play out as follows: Anthropologists would enter into a traditional village and record the various traditions using culture as the only measurement to explain behaviour. Often, the community involved would be functioning on a so-called 'non-Christian' level. Using their own value systems as a point of reference, researchers could then justify the community's need for religious conversion and consequently missionary work would be undertaken. The interviewee viewed this as a simplistic way of explaining people's behaviour and juxtaposed it with a curriculum that focuses more on the social aspects of studying people within a broader sense of the context.

This kind of anthropology examines broader socio-political factors and is more problemClaire Wagner and David Maree 


\section{openUP}

oriented in thinking. In other words, the formulation of a research question is often based on a problem-oriented background instead of trying to do a straightforward ethnography (explaining a certain group of people's culture according to its cultural position, values, and worldview). A straightforward ethnographic approach also places the researcher outside the context in the role of an outsider. By critiquing traditional research courses and transforming their curricula to suit this critique, some anthropology departments have also made adjustments to their research courses. Ways in which this political repositioning of anthropology informs the undergraduate research curriculum are, for example, the addition of new methods to the content (such as focus group discussions and narrative ethnography), and changing the construction of power relationships between the researcher and the researched (such as also giving the informant a voice when recording or writing down observations).

An interviewee in industrial psychology provided another example of socio-political positioning. According to the interviewee, there were two psychology societies before the 1970s, one for English speakers and the other for Afrikaans speakers. These two groups merged in the 1970s, but the two camps were still evident and had ideological debates on how to teach psychology. English universities integrated all areas of psychology while Afrikaans universities separated different types of psychology, keeping industrial psychology separate, for example. In the course of attending psychology conferences, the interviewee noticed that English universities focused on undergraduate training in research methodology so that students built on their knowledge from the beginning of their studies. In the experience of this interviewee, Afrikaans universities only included research methodology on a postgraduate level in the form of statistical methods, while English institutions were developing a critical mindset in their students from an early stage. Critical thinking is therefore seen as an added outcome of research courses.

South Africa's social context is also seen as a metaphor for curriculum development. As one participant puts it:

We are confronted every second with diversity in terms of race, culture, politics, and history. Why in God's name do we want to stick to one paradigm when it comes to academia and ignore realities?

Training students in different worldviews is thus equated with the socio-political paradigm shift made in this country from the exclusion of difference (or alternative ways of thinking) to acknowledging the validity of the diverse South African context.

\section{CONCLUSIONS: THE WAY FORWARD FOR PSYCHOLOGY AND RESEARCH METHODOLOGY CURRICULA}

The way in which undergraduate research courses are constructed is probably relevant to many other curricula. Research methodology in the social sciences needs to adapt to the transformations taking place in society, and should recognise the effects these changes have 


\section{openUP}

on higher education in general (Brew, 2003; Tashakkori \& Teddlie, 2003). As authors, we are attempting to push psychology to the forefront of bringing about changes in academic society. Psychology may, however, also need to attend to internal changes, as indicated by Bradley (1998, p. 87):

If psychology is to reconstruct its relationship to the reproduction of the present, then psychology needs to change the way it reproduces itself. It needs to create a space for experience in which subjects can become aware of the obstacles that collectively serve to impede their development. No longer can the psychologist be 'the one supposed to know', imposing knowledge from above. They must find a way of accessing the 'view from below'. Which means they must find a way of undoing the hegemony of the sublime, in pedagogy as well as research.

It is hoped that this article will stimulate refection and debate about alternative paths for constructing research methodology curricula. Some warnings should be heeded, however. As Muller (2000) points out, there is the danger that a critical analysis could promise too much but not be able to deliver on these promises. A researcher cannot simply deliver a critical perspective and then expect the world to change on the strength of these 'new insights'. People are not always open to change for a variety of reasons, such as feeling content with their current viewpoints and actions or not wanting to admit to 'uncomfortable realities' (Muller, p. 137). Initiatives for change could thus meet with resistance.

Nevertheless, instructors of research courses for psychology students at universities in South Africa should recognise that methodological debates in the social sciences and current thinking about knowledge and learning are pointing to new (although not necessarily better) directions in how we should prepare students for studying the human realm. These include training undergraduate students to become good consumers instead of practitioners of research (Porte, 2002), forging research partnerships between higher education institutions, industry, and the state (Kraak, 1997), transforming curricula to the Mode 2 model of knowledge production where students are shaped into innovators (Gibbons, Limoges, Nowotny, Schwartzman, Scott, \& Trow, 1994), and so on. Some may argue that the purpose of undergraduate courses is to introduce students to topics - and thus that a graduate should not necessarily be trained to change the world - but we maintain that awareness is required of the reasons why we construct current research curricula in a certain way. If we want to remain relevant to the social world in which we live, we need to discuss these directions and forge a new way of acting in this world.

Two specific implications for the road ahead are envisaged:

\section{Investigating the interplay between practice and academia}

As this article has argued that the construction of undergraduate research courses relies solely on the expertise of lecturers, academia may benefit from investigating how methodology curricula relate to workplace practices and requirements. Although the aim of an undergraduate research course may not necessarily be to train students to become 


\section{openUP}

agents of social change (or even to be research practitioners), conducting research on the extent of competence required of social science graduates when they enter the private sector, government, or other workplaces could be an additional way of informing curriculum design. Furthermore, if a participatory research design is followed, students become equal, reflective partners with lecturers and contribute to understanding what role, if any, practice could play in improving current courses.

\section{Participating in dialogues about teaching research methodology}

While individual lecturers could reflect on the content of their research courses using various techniques, dialogical activities or 'mass' refection on the teaching of methodology in psychology (and the broader social sciences) may also be useful. This dialogue should not reproduce the notion of the researcher as expert teacher, but should challenge fellow academics to consider and discuss the assumptions that underlie curricula and how effective these assumptions are. For example, Wagner and Okeke (2006) argue that academics need to reflect on the reasons why they include certain content (such as quantitative and qualitative methodologies) in their courses.

\section{REFERENCES}

Bhana, A. (1999). Participatory action research: A practical guide for realistic radicals. In M. Terre Blanche \& K. Durrheim (Eds.), Research in practice: Applied methods for the social sciences (pp. 227-238). Cape Town: UCT Press.

Bradley, B. (1998). Two ways to talk about change: 'The child' of the sublime versus radical pedagogy. In B. M. Bayer \& J. Shotter (Eds.), Reconstructing the psychological subject: Bodies, practices and technologies (pp. 68-93). London: Sage. Brew, A. (2003). Teaching and research: New relationships and their implications for inquiry-based teaching and learning in higher education. Higher Education Research \& Development, 22(1), 3-18.

Carspecken, P. F. (1996). Critical ethnography in educational research: A theoretical and practical guide. New York: Routledge.

Chin, J. L., \& Russo, N. F. (1997). Feminist curriculum development: Principles and resources. In J. Worell \& N. G. Johnson (Eds.), Shaping the future of feminist psychology: Education, research, and practice (pp. 93-120). Washington, DC: American Psychological Association. Department of Arts, Culture, Science and Technology. (1996). White paper on science and technology: Preparing for the twentyfirst century. Pretoria: Government Printer. Retrieved July 20, 2002, from http://www.gov.za/whitepaper/1997/sc\&tecwp.htm

Gadamer, H. G. (1989). Truth and method (2nd ed.). (J. Weinsheimer \& D. G. Marshall, Trans.). New York: Crossroad. (Original work published 1960).

Gibbons, M., Limoges, C., Nowotny, H., Schwartzman, S., Scott, P., \& Trow, M. (1994). The new production of knowledge: The dynamics of science and research in contemporary societies. Thousand Oaks, CA: Sage.

Honneth, A. (1999). The social dynamics of disrespect: Situating critical theory today. In P. Dews (Ed.), Habermas. A critical reader (pp. 320-337). Oxford: Blackwell. 
Kelly, K. (1999). Hermeneutics in actionęmpdttPy and interpretation in qualitative research. In M. Terre Blanche \& K. Durrheim (Eds.), Research in practice: Applied methods for the social sciences (pp. 398-420). Cape Town: UCT Press.

Kincheloe, J. L., \& McClaren, P. (2000). Rethinking critical theory and qualitative research. In N. K. Denzin \& Y. S. Lincoln (Eds.), Handbook of qualitative research (2nd ed.) (pp. 279-313). Thousand Oaks, CA: Sage.

Kraak, A. (1997). Globalisation, changes in knowledge production, and the transformation of higher education. In N. Cloete, J. Muller, M. W. Makgoba, \& D. Ekong (Eds.), Knowledge, identity and curriculum transformation in Africa (pp. 51-78). Cape Town: Maskew Miller Longman.

Lyotard, J. F. (1984). The postmodern condition: A report on knowledge (G. Bennington \& B. Massumi, Trans.). Manchester: Manchester University Press. (Original work published 1979).

McCarthy, T. (1994). The critique of impure reason: Foucault and the Frankfurt school. In M. Kelly (Ed.), Critique and power: Recasting the Foucault/Habermas debate (pp. 243-282). Cambridge, MA: MIT Press.

Mourad, R. P. (1997). Postmodern interdisciplinarity. The Review of Higher Education, 20(2), 113-140.

Muller, J. (2000). Reclaiming knowledge: Social theory, curriculum and education policy. London: Routledge.

Porte, G. K. (2002). Appraising research in second language learning: A practical approach to critical analysis of quantitative research. Amsterdam: Benjamins.

Schubert, W. H. (1986). Curriculum, perspective, paradigm, and possibility. New York: Macmillan.

Silverman, D. (1993). Interpreting qualitative data: Methods for analysing talk, text, and interaction. London: Sage.

Stanovich, K. E. (2004). How to think straight about psychology (7th ed.). Boston, MA:

Allyn \& Bacon. Tashakkori, A., \& Teddlie, C. (2003). Issues and dilemmas in teaching research methods courses in social and behavioural sciences: US perspective. International Journal of Social Research Methodology, 6(1), 61-77.

Tothill, A., \& Crothers, C. (1997). Report on social science research methodology teaching at South African tertiary institutions. (Compiled on behalf of the CSD's research methodology audit team). Pretoria: Human Sciences Research Council.

Van Staden, F., \& Visser, D. (1990). Analysis of themes and statistical techniques. South African Journal of Psychology, 20(1), 47-55.

Van Staden, F., \& Visser, D. (1992). Comparison of methodology used in contributions 


\section{openUP}

to the South African journals of education, psychology and sociology. South African Journal of Science, 88(1), 76-77.

Visser, D., \& Van Staden, F. (1990). Analysis of sample selection, sample composition and research design. South African Journal of Psychology, 20(2), 111-119.

Wagner, C. (2003). Placing psychology: A critical exploration of research methodology curricula in the social sciences. Unpublished DPhil thesis, University of Pretoria.

Wagner, C., \& Okeke, C. (2006). Quantitative or qualitative: Ontological and epistemological choices in research methodology curricula. Unpublished manuscript.

Williams, M. (2000). Social research: The emergence of a discipline? International Journal of Social Research Methodology, 3(2), 157-166.

Willig, C. (2001). Introducing qualitative research in psychology: Adventures in theory and method. Buckingham: Open University Press. 